\title{
Hourly Profiles of Air Pollution Variation in Selected Cities, Towns and Villages in Poland
}

\author{
Robert Cichowicz ${ }^{1, *}$, Artur Stelegowski ${ }^{1}$ \\ ${ }^{1}$ Lodz University of Technology, Faculty of Civil Engineering, Architecture and Environmental Engineering, Lodz, Poland
}

\begin{abstract}
Concentration of air pollution in urbanized and agricultural areas is related to the activity of various economy sectors (the so-called SNAP categories). Therefore, the change in the emission of pollutants by an anthropogenic source should result in a change in the air pollution level in the selected area. To better understand the nature of changes in air pollution concentration in urban and agricultural areas, an analysis of data of five-year (2012-2016) air quality measurements, carried out at selected automatic air quality monitoring stations in Poland, Europe. The data came from stations located in 5 regions (Lower Silesia, Greater Poland, Lodz, Masovia and Lublin) in central Poland. The average hourly concentrations in selected areas in cities, towns and villages were compared with the hourly emission factors of power generation sector (SNAP1), residential and commercial combustion sector (SNAP2) and road transport sector (SNAP7). The hourly profiles of air pollution level were expressed by means of the "imission factor", as analogous to the hourly profiles of the "emission factor" that is being used in the LOTOS-EUROS and the CHIMERE chemistry-transport models.
\end{abstract}

\section{Introduction}

Air pollution negatively affects both human health and the condition of the vegetation [1-2]. Therefore, there are legal acts in various regions of the World, including Europe, where permissible hourly, daily and yearly levels of air pollutants are determined [3]. However, concentrations of air pollutants in a given area change hour by hour [4-6], because they result from the impact of many factors. Often none of which is major. Therefore, changes in the concentration of air pollutants usually depend on both variable meteorological conditions $[4,78]$, natural sources of pollutant emissions [9], as well as relatively constant profiles of human activity and the resulting changes in anthropogenic pollutant emissions [10-12]. Daily activity of various economy sectors, and thus sources of pollution, can be expressed using fixed emission profiles. For example, temporal profiles used in air pollution/chemistry transport models, such as 'Long Term Ozone Simulation - European Operational Smog' (LOTOS-EUROS) [12-13] and CHIMERE [11]. Those temporal profiles are made for anthropogenic emission sources listed in the 'Selected Nomenclature for Air Pollution' (SNAP) categories (Fig. 1) [13-16]. The measurement and / or modelling results allow to determine the average daily variations of air pollutants concentrations [11,17-18]. Averaging the data from a large data base of experimental measurements should allow the independence of results from dynamic changes in meteorological conditions, as well as from human activity on a given day. By this means become possible obtaining "typical" daily profiles of air pollution concentration in a given location, to assess the daily variation of the air quality.

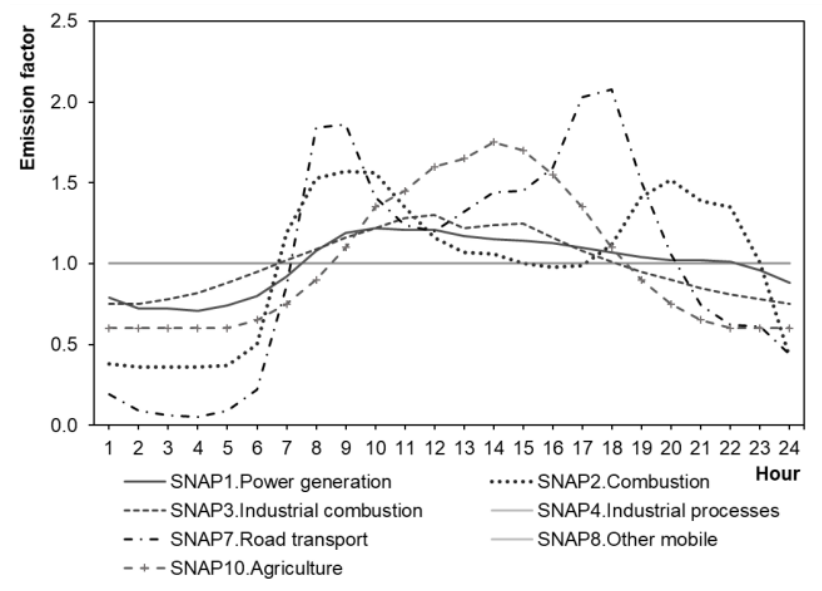

Fig. 1. Hourly emission factors for selected activity sectors (SNAP) $[13,15]$.

Poland is located in the Central-Eastern Europe, in the temperate continental climate zone. Due to the long heating period (about 6-8 months), the contribution of air pollutant emissions from residential and commercial combustion, for the purpose of building heating, is significant (especially in the winter periods). While in the rest of the year (mainly in the summer periods) prevails the emission from transport and power generation. The majority of energy (91\%) comes from non-renewable sources: coal (50\%), crude oil (26\%) and natural gas (15\%). Therefore, the main anthropogenic sources of air pollution in Poland are, among others, power industry (SNAP1), non-industrial combustion (SNAP 2) and road transport (SNAP 7) (Table 1). As a consequence,

\footnotetext{
* Corresponding author: robert.cichowicz@p.lodz.pl
} 
the permissible levels of pollutants, especially dust, are often exceeded [19].

Table 1. Contribution of SNAP activity sectors in the total air pollution level in Poland [20].

\begin{tabular}{|c|c|}
\hline Pollution & Activity sector (SNAP) \\
\hline $\mathrm{NO}_{\mathrm{x}}$ & SNAP7 (32\%), SNAP1 (31\%), SNAP8 (13\%) \\
\hline $\mathrm{SO}_{2}$ & SNAP1 (47\%), SNAP2 (34\%), SNAP3 (18\%) \\
\hline $\mathrm{CO}$ & SNAP2 (64\%), SNAP7 (20\%), SNAP3 (9\%) \\
\hline $\mathrm{PM}_{10}$ & SNAP2 (50\%), SNAP1 (10\%), SNAP7 (9\%) \\
\hline $\mathrm{PM}_{2.5}$ & SNAP2 (51\%), SNAP7 (13\%), SNAP1 (10\%) \\
\hline
\end{tabular}

The aim of this analysis was to determine the average hourly variations in concentrations of selected air pollutants, compared to the activity profiles of main anthropogenic emission sources (SNAP1, SNAP2, SNAP7) in the given areas.

\section{Method Description}

The analysis was carried out for the experimental measurements from 2012-2016, from selected automatic air quality monitoring stations in central Poland, Europe. The average daily variations in concentrations of $\mathrm{PM}_{10}$ and $\mathrm{PM}_{2.5}, \mathrm{NO}_{\mathrm{x}}$ and $\mathrm{NO}_{2}, \mathrm{SO}_{2}$ and $\mathrm{CO}$ were analysed. Data regarding the analysed pollutants came from a total of 22 monitoring stations in 5 voivodships (Lower Silesian, Greater Poland, Lodz, Mazovian and Lublin) in central Poland. The measuring stations were divided, due to the characteristics of the area, into groups: urban traffic (UT), city background (CB), suburban background (SB), town background (TB) and rural background (RB) (Tables 2-4). Also, the data was assigned to the winter period, lasting 6 months (from October to March), and summer, lasting 4 months (from May to August). However, only the data with at least $75 \%$ completeness, for a given measurement station in a given, was used for the calculation. However, no information of $\mathrm{PM}_{2.5}$ concentrations was obtained at $\mathrm{RB}$ stations due to the lack of data from air quality monitoring.

Table 2. Location of measurement stations in cities.

\begin{tabular}{|c|c|c|}
\hline Voivodeship & $\begin{array}{c}\text { City, station } \\
\text { type }\end{array}$ & Population \\
\hline Lower Silesian & $\begin{array}{c}\text { Wroclaw, } \\
\text { UT, CB, SB }\end{array}$ & 639,000 \\
\hline Greater Poland & $\begin{array}{c}\text { Poznan, } \\
\text { CB, SB }\end{array}$ & 539,000 \\
\hline Lodz & $\begin{array}{c}\text { Lodz, } \\
\text { UT, CB, SB } \\
\text { Warsaw, } \\
\text { UT, CB, SB } \\
\text { Lublin, } \\
\text { CB }\end{array}$ & 690,000 \\
\hline Lublin & \multicolumn{2}{|c|}{340,000} \\
\hline
\end{tabular}

Table 3. Location of measurement stations in towns.

\begin{tabular}{|c|c|c|}
\hline Voivodeship & $\begin{array}{c}\text { City, station } \\
\text { type }\end{array}$ & Population \\
\hline Lower Silesia & $\begin{array}{c}\text { Klodzko, } \\
\text { TB }\end{array}$ & 27,000 \\
\hline Greater Poland & $\begin{array}{c}\text { Konin, } \\
\text { TB }\end{array}$ & 75,000 \\
\hline Lodz & $\begin{array}{c}\text { Piotrkow Tryb., } \\
\text { TB }\end{array}$ & 74,000 \\
\hline Masovia & $\begin{array}{c}\text { Piastow, } \\
\text { TB }\end{array}$ & 23,000 \\
\hline Lublin & $\begin{array}{c}\text { Biala Podlaska, } \\
\text { TB }\end{array}$ & 57,000 \\
\hline
\end{tabular}

Table 4. Location of measurement stations in villages.

\begin{tabular}{|c|c|c|}
\hline Voivodeship & $\begin{array}{c}\text { City, station } \\
\text { type }\end{array}$ & Population \\
\hline Lower Silesia & $\begin{array}{c}\text { Osieczow, } \\
\text { RB }\end{array}$ & 345 \\
\hline Greater Poland & $\begin{array}{c}\text { Piaski, } \\
\text { RB }\end{array}$ & 124 \\
\hline Lodz & $\begin{array}{c}\text { Gajew, } \\
\text { RB }\end{array}$ & 114 \\
\hline Masovia & $\begin{array}{c}\text { Belsk Duzy, } \\
\text { RB }\end{array}$ & 790 \\
\hline Lublin & $\begin{array}{c}\text { Obrocz, } \\
\text { RB }\end{array}$ \\
\hline
\end{tabular}

Hourly profiles of air pollution variation were calculated by means of the "imission factor". The methodology presented in this study was based on the realistic hourly emission profile calculation, used by Menut el at. for the optimization of temporal profiles of road transport emissions in Europe [11]. Therefore, the 'typical' diurnal profiles of air pollutants were calculated considering the 'background' pollution in the analysed locations. The 'background' was defined as the lowest measured value of the day [11]. The "typical" hourly variations were determined by means of the imission factor (IF), using the equation (1):

where:

$$
I F_{h, k}=\frac{C_{h, k}-C_{\min , k}}{C_{m, k}-C_{\min , k}}
$$

$I F_{h, k}$ - imision factor for given hour and day,

$C_{h, k}$ - concentration of the air pollutant;

$C_{m i n, k}$ - the lowest daily concentration of pollutant;

$C_{m, k}$ - daily mean concentration of pollutant.

The typical daily profiles of pollution variation were calculated by averaging the hourly concentrations from the 2012-2016 period. Therefore, the resultant imission factor was calculated as the average of all $\mathrm{IF}_{\mathrm{h}, \mathrm{k}}$ for the given hour. For example, the imission factor at $\mathrm{CB}$ stations for the 
typical Wednesday at 20:00 (CET), was calculated as the average of all values for a given pollutant occurring at $\mathrm{CB}$ stations on Wednesdays at 20:00 (CET), and the IF $=1$ means the daily average.

\section{Results}

Daily variations of air pollution were compared with the hourly emission profiles for road transport (SNAP7) in summer, and non-industrial combustion (SNAP2) and transport (SNAP7) in winter. Additionally, the emission profile for the power industry (SNAP1) was compared with hourly profiles of $\mathrm{NO}_{\mathrm{x}}, \mathrm{SO}_{2}, \mathrm{PM}_{10}$ and $\mathrm{PM}_{2.5}$.

The main sources of $\mathrm{NO}_{\mathrm{x}}$ emissions in Poland were road transport and non-industrial combustion (Table 1). What is puzzling, the $\mathrm{NO}_{\mathrm{x}}$ profiles (Figs. 2-3) were similar to the SNAP2 profile. However, this sector was not related to $\mathrm{NO}_{x}$ emission. What is more, there was no similarity of $\mathrm{NO}_{\mathrm{x}}$ profiles to SNAP1 profiles. The distribution of $\mathrm{NO}_{\mathrm{x}}$ was alike at $\mathrm{CB}, \mathrm{SB}$ and $\mathrm{TB}$ stations, which indicated a similar nature of the spread of nitrogen oxides in those areas. The imission factor was from 0.19 to 1.61 in the winter. Values above the average occurred at $\mathrm{CB}, \mathrm{SB}$ and $\mathrm{TB}$ stations at 7:00-11:00 and 15:00-23:00, at UT stations at 7:00-23:00, and at RB stations at 16:00-1:00. In the summer, the IF was from 0.31 to 1.98. High concentrations occurred at 6:00-10:00 and 15:00-23:00 (UT stations), at 19:00-8:00 (TB and RB), 5:00-9:00 and 19:00-2:00 (CB and SB stations). Therefore, in these periods, people were more likely exposed in the given areas to an adverse effect of high $\mathrm{NO}_{\mathrm{x}}$ concentrations, than at the other hours.

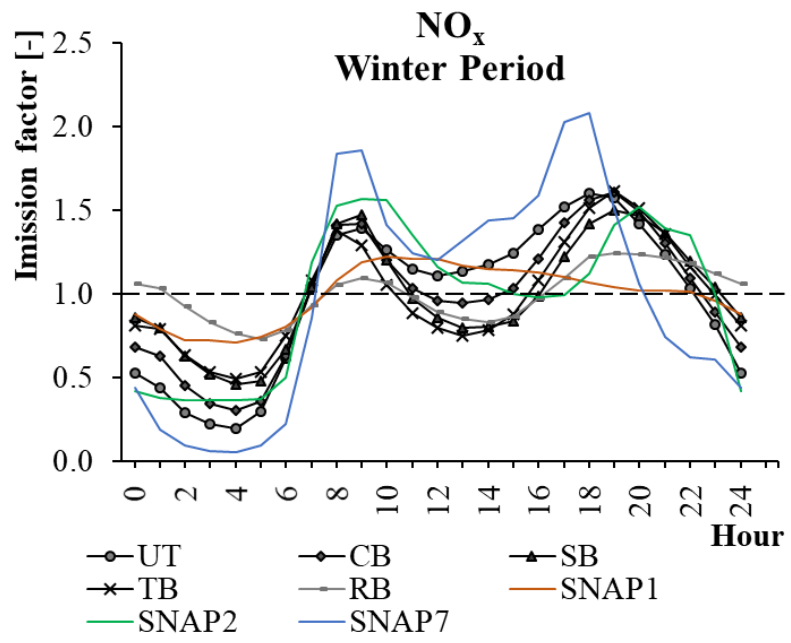

Fig. 2. Hourly profiles of $\mathrm{NO}_{\mathrm{x}}$ variation in winter periods.

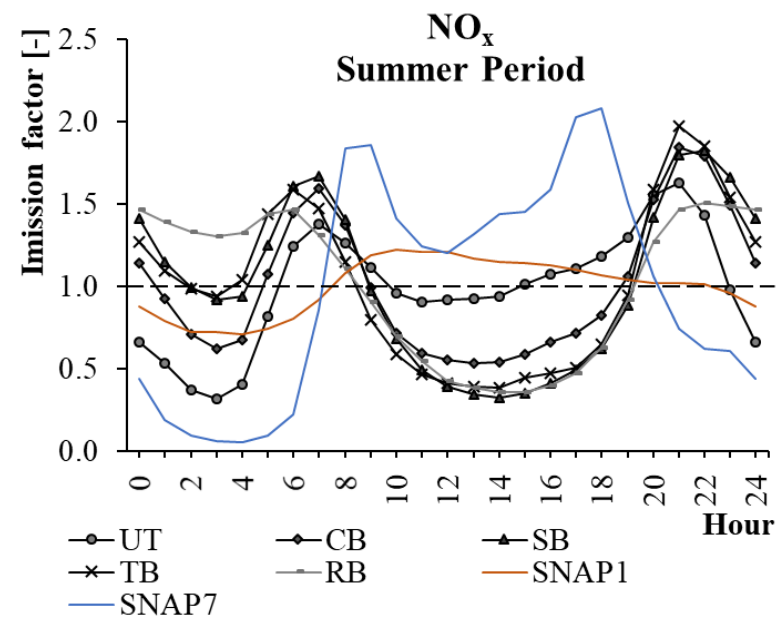

Fig. 3. Hourly profiles of $\mathrm{NO}_{\mathrm{x}}$ variation in summer periods.

The $\mathrm{NO}_{2}$ variations (Figs. 4-5) differed from both the SNAP2 and the SNAP7 profiles. This showed the lack of major influence of these sectors on hourly changes in $\mathrm{NO}_{2}$ concentration. However, the $\mathrm{CB}, \mathrm{SB}$ and $\mathrm{TB}$ profiles were alike, which could indicate a similar nature of the spread of the air pollution in these areas. But different at UT and RB stations, probably due to differences in emissions from road traffic. In winter, high $\mathrm{NO}_{2}$ concentrations (IF up to 1.73) occurred usually at around 7:00-10:00 and at 15:00-23:00 (CB, SB and TB stations), at 7:00-23:00 (UT stations), and at 16:00-2:00 (RB stations). However, in the summer the IF was up 2.23, and high NO2 concentrations occurred at 6:00-8:00 and 15:00-23:00 (UT stations), at 19:00-8:00 (TB and RB stations), at 5:00-8:00 and at 19:00-2:00 (CB and SB stations). Thus, at the other period of the day, the $\mathrm{NO}_{2}$ concentrations could be expected to be lower (IF > 0.24 in winter and $>0.34$ in summer) than the daily average.

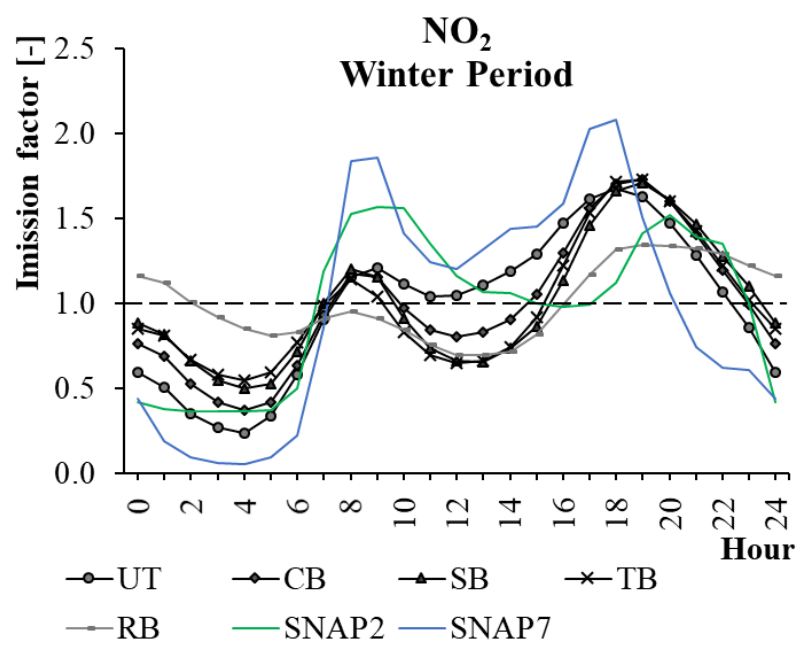

Fig. 4. Hourly profiles of $\mathrm{NO}_{2}$ variation in winter periods. 


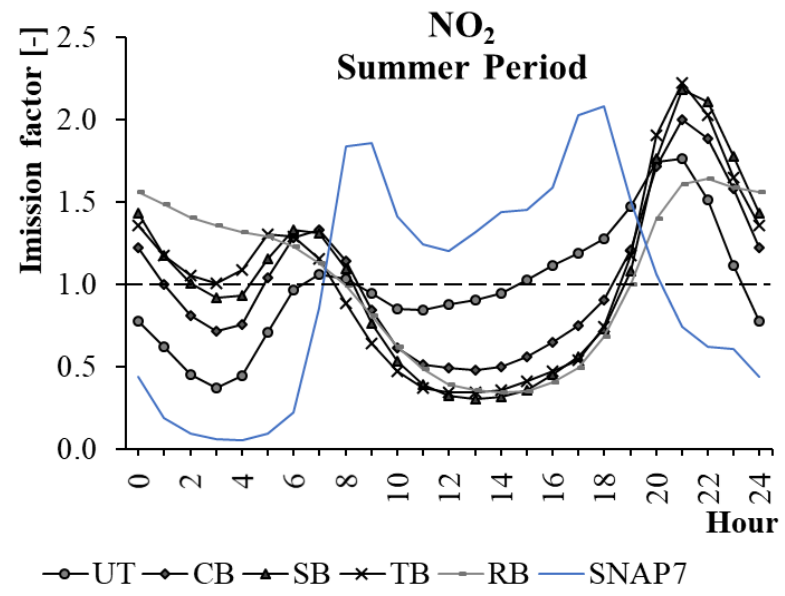

Fig. 5. Hourly profiles of $\mathrm{NO}_{2}$ variation in summer periods.

The main sources of $\mathrm{SO}_{2}$ emissions in Poland were power industry and non-industrial combustion (Table 1). Therefore, the profiles of $\mathrm{SO}_{2}$ (Figs. 6-7) at $\mathrm{CB}, \mathrm{SB}, \mathrm{TB}$ and $\mathrm{RB}$ stations in the summer periods were similar to the SNAP1 profile. However, in the winter it was possible to observe an increase in $\mathrm{SO}_{2}$ concentration in two periods of the day, around 12:00 and 20:00, which could indicate the effect of SNAP2 activity (peaks at 10:00 and 20:00). The IF was $0.59-1.66$ in the winter periods, and $0.34-1.54$ in the summer periods.

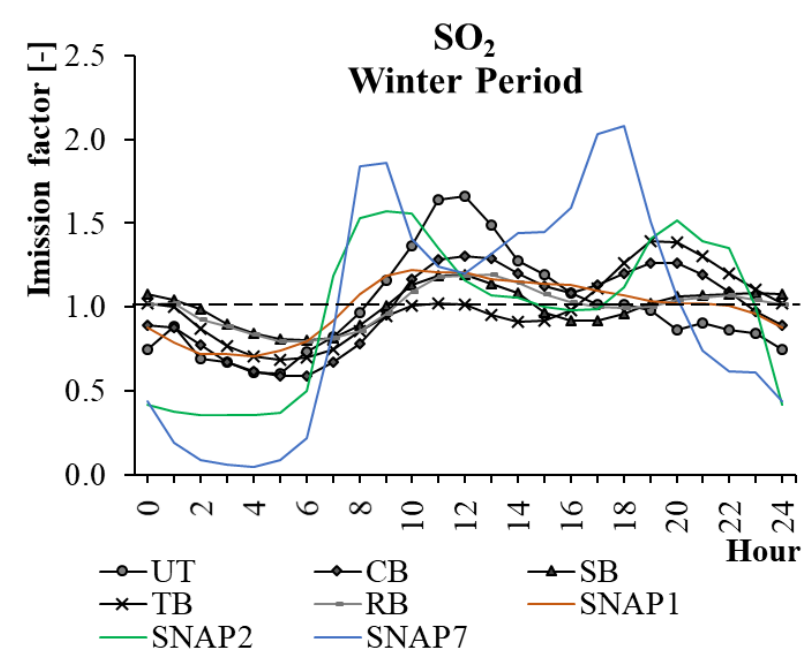

Fig. 6. Hourly profiles of $\mathrm{SO}_{2}$ variation in winter periods.

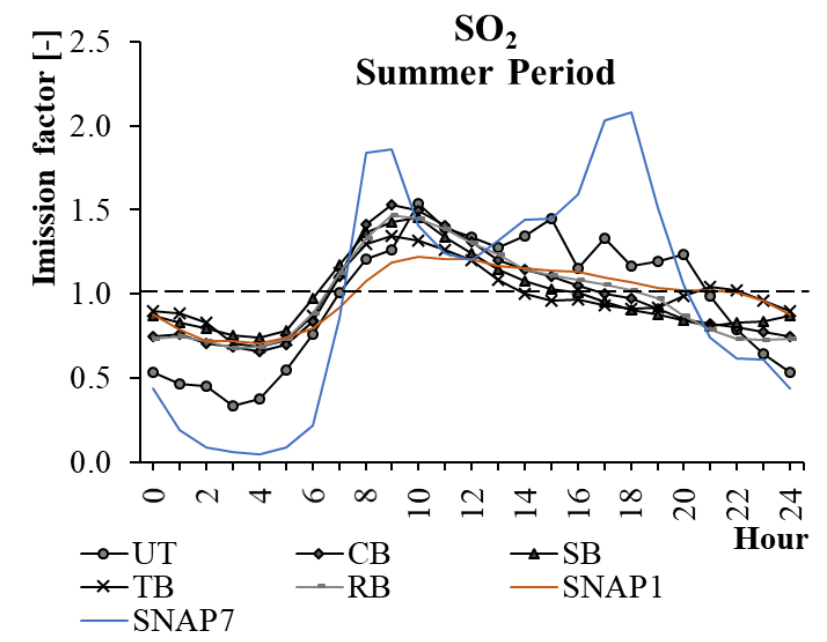

Fig. 7. Hourly profiles of $\mathrm{SO}_{2}$ variation in summer periods.

The main sources of $\mathrm{CO}$ emissions were non-industrial combustion and road transport (Table 1). However, the CO profiles (Figs. 8-9) were different the SNAP2 and SNAP7 profiles. All types of stations were characterized by a similar distribution. The $\mathrm{CB}, \mathrm{SB}$ and, TB stations showed a large similarity to each other, probably due to the similar nature of emission from transport and combustion. The $\mathrm{CO}$ variations were the smallest at the RB stations (IF $0.60-1.43$ in the winter and $0.64-1.32$ in the summer), and at the largest at the UT stations (IF 0.34-1.65 in the winter and $0.32-1.82$ in the summer). This could indicate a high impact of car traffic on changes in CO concentration during a typical day.

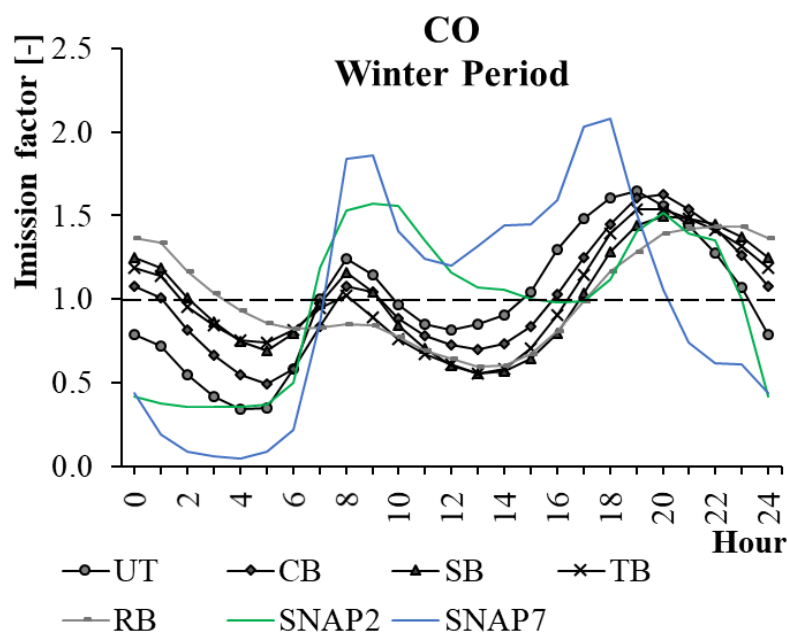

Fig. 8. Hourly profiles of $\mathrm{CO}$ variation in winter periods. 


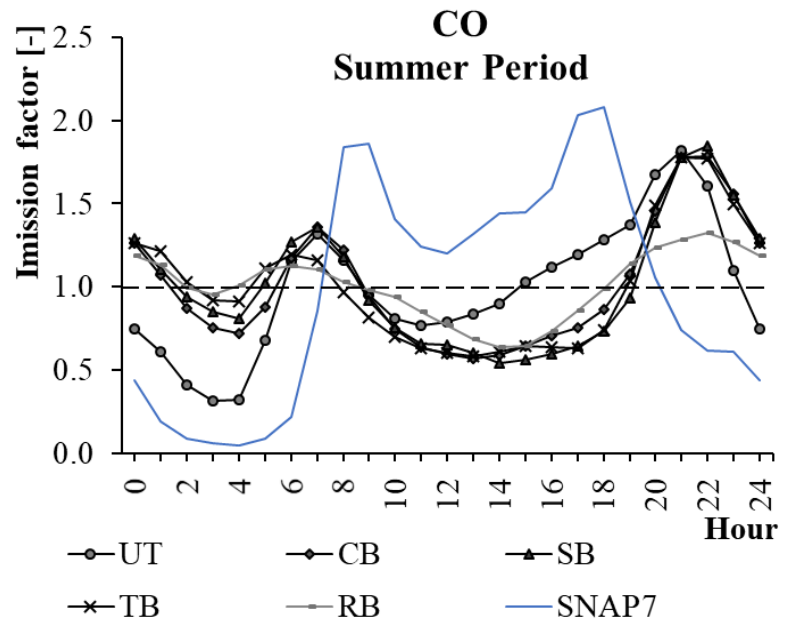

Fig. 9. Hourly profiles of $\mathrm{CO}$ variation in summer periods.

Currently, high concentrations of particulate matter are one of the biggest problems of air quality in Poland, mainly related to the activity of the SNAP1, SNAP2 and SNAP7 sectors (Table 1). However, the analysis did not show much similarity between the $\mathrm{PM}_{10}$ (Figs. 10-11) and $\mathrm{PM}_{2.5}$ profiles (Figs. 12-13), and the hourly profiles of the SNAP categories. This was probably due to simultaneous overlap of those factors and the impact of meteorological conditions. Daily variation of the particulate matter concentration was relatively small, compared to other pollutants analysed, and the IF for $\mathrm{PM}_{10}$ comprised between $0.52-1.41$ during the winter period, and $0.63-1.36$ during the summer period. However, values higher than the daily mean occurred mainly at night. On the other hand, values below the daily mean occurred in the winter, from around 4:00 to 17:00, and in the summer from approximately 9:00 to 20:00. What is worth noticing, all types of stations were characterized by similar profiles of $\mathrm{PM}_{10}$ and $\mathrm{PM}_{2.5}$, which could indicate the major influence of meteorological conditions on the persistence of dust in the air

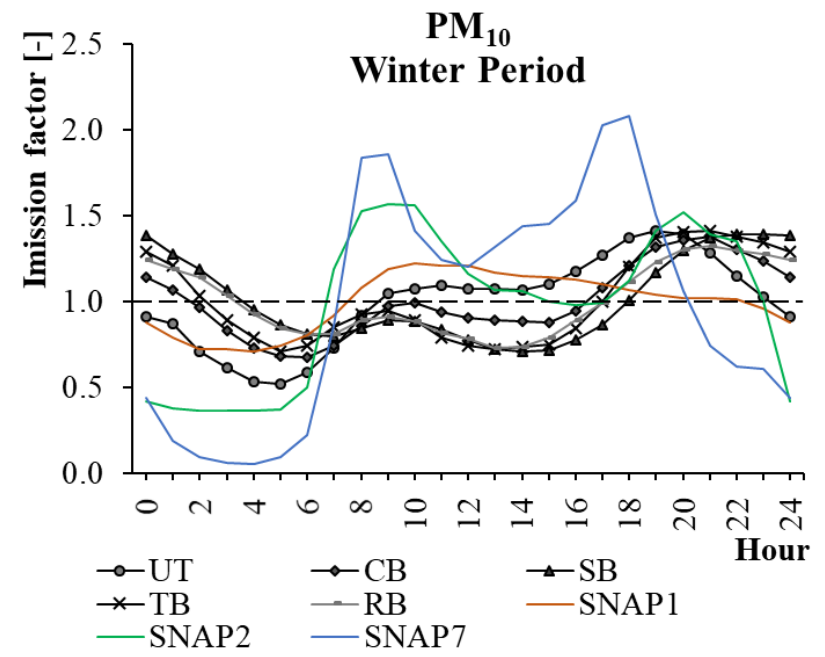

Fig. 10. Hourly profiles of $\mathrm{PM}_{10}$ variation in winter periods.

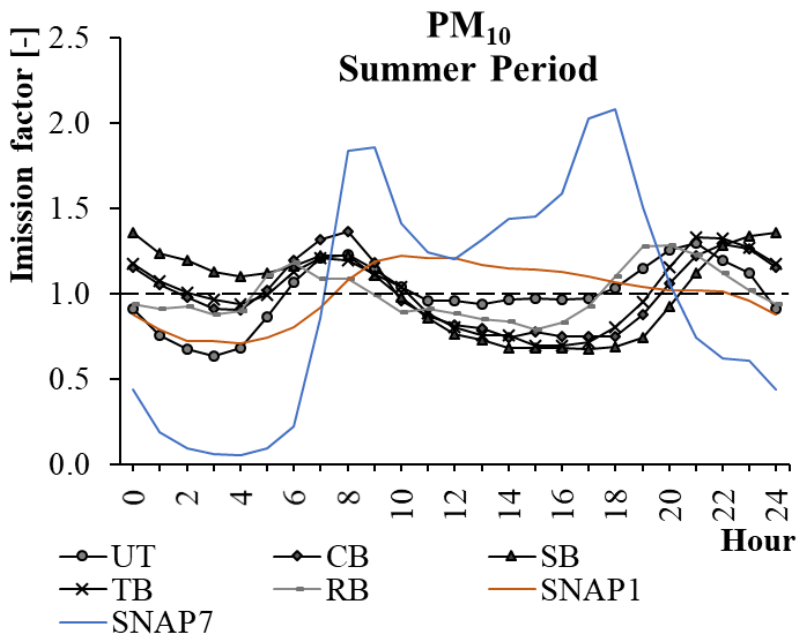

Fig. 11. Hourly profiles of $\mathrm{PM}_{10}$ variation in summer periods.

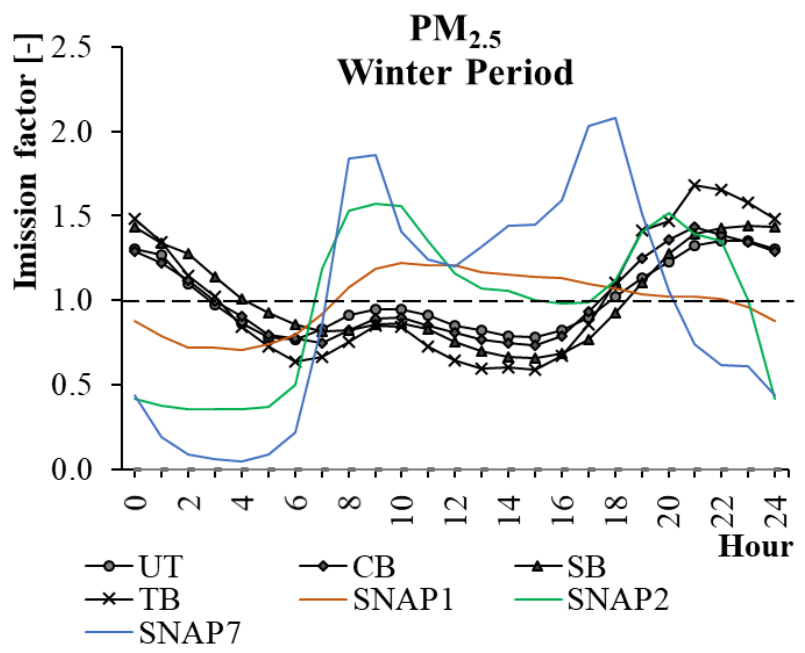

Fig. 12. Hourly profiles of $\mathrm{PM}_{2.5}$ variation in winter periods.

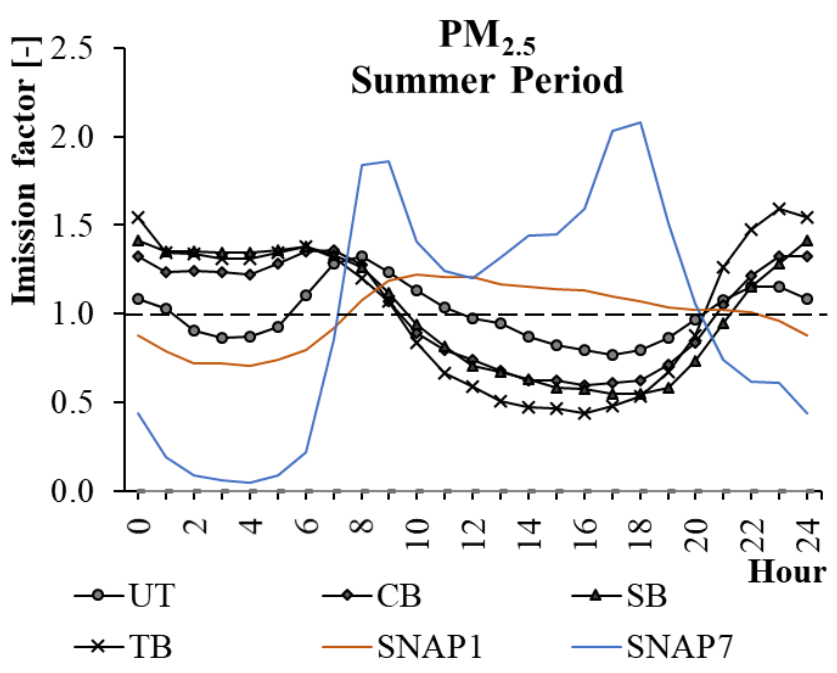

Fig. 13. Hourly profiles of $\mathrm{PM}_{2.5}$ variation in summer periods. 


\section{Conclusions}

After carrying out the analysis, it can be concluded that the concentrations of the selected air pollutants varied significantly during a "typical" winter and summer day. The nature of changes in the winter was different than in the summer. The mean hourly concentration values ranged from around 0.2 to 2.2 times the day average. The highest daily variations occurred in the case of $\mathrm{NO}_{\mathrm{x}}$ and $\mathrm{NO}_{2}$, and the lowest in the case of $\mathrm{PM}_{10}$ and $\mathrm{PM}_{2.5}$. What is puzzling, the relative changes in the summer were greater than in the winter, probably due to lower daily minimum values. It was observed that measuring stations located in cities $(\mathrm{CB}, \mathrm{SB})$ and in towns (TB) were characterized by profiles similar to each other. On the other hand, hourly profiles at urban traffic stations in the cities (UT), and at stations located in the villages (RB), differed the most. However, despite significant differences in the level of air pollution in cities and in villages, the hourly profiles indicated a similar nature of spread of pollutants in those areas.

The analysis focuses on the impact of air pollutant emissions from anthropogenic sources, and there were no significant similarities between the hourly profiles of air pollution and the SNAP1, SNAP2 and SNAP7 profiles. The exceptions were $\mathrm{NO}_{\mathrm{x}}$ and SNAP2 in winter, and $\mathrm{SO}_{2}$ and SNAP1 in summer. While the $\mathrm{SO}_{2}$ concentrations were surely related to the activity of the power generation sector (SNAP1), then the $\mathrm{NO}_{\mathrm{x}}$ concentrations should not be related to the non-industrial combustion (SNAP2). However, hourly profiles of pollutant concentration may vary significantly, depending on the characteristics of air pollution in a given city.

To conclude, the calculated "imission factor" can be used to estimate the concentration of pollutants in a given hour, based on known daily- or annual-mean values. The developed profiles may help to determine typical periods in which the level of air pollution is lower/higher than the average. The information of hourly variations of air pollution can also help to understand the differences and similarities between the nature of daily variations in the local concentration of nitrogen oxides, sulfur dioxide, carbon monoxide and dust in urban areas (near roads, in city centers and on their suburbs), in towns, and in villages. This is especially important for citizens of countries, whose economy, as in Poland, is based on fossil fuels, especially on coal and lignite. However, increasing the contribution of renewable and alternative energy sources in those regions may lead to a significant reduction in concentrations of air pollutants, and consequently may affect the hourly profiles of air pollution.

\section{References}

1. WHO, Air Quality Guidelines for Europe (Copenhagen, WHO Regional Publications, 2000)

2. WHO, Air Quality Guidelines for Europe. Global Update 2005 (Copenhagen, WHO Regional Publications 2005)
3. Directive 2008/50/EC of the European Parliament and of the Council of 21 May 2008 On Ambient Air Quality and Cleaner Air for Europe (OJ L 152, 11.6.2008)

4. J. Guo, F. Xia, Y. Zhang, H. Liu, J. Li, M. Lou, ..., P. Zhai, Impact of diurnal variability and meteorological factors on the PM2.5 - AOD relationship: Implications for PM2.5 remote sensing Environmental Pollution 221, 94-104 (2017) doi:10.1016/j.envpol.2016.11.043

5. R. Cichowicz, G. Wielgosiński G, Analysis of variations in air pollution fields in selected cities in Poland and Germany ECOL CHEM ENG S 25, 217-27 (2018) doi:10.1515/eces-2018-0014

6. M. Liu, J. Lin, Y. Wang, Y. Sun, B. Zheng, J. Shao J, ..., Z. Wu, Spatiotemporal variability of NO2 and PM2.5 over eastern China: Observational and model analyses with a novel statistical method, Atmospheric Chemistry and Physics 18 12933-52 (2018) doi:10.5194/acp-18-12933-2018

7. N. Pérez, J. Pey, M. Cusack, C. Reche, X. Querol, A. Alastuey, M. Viana, Variability of particle number, black carbon, and PM10, PM 2.5, and PM1 levels and speciation: Influence of road traffic emissions on urban air quality, Aerosol Science and Technology 44, 487-99 (2010) doi:10.1080/02786821003758286

8. R. Cichowicz, G. Wielgosiński, W. Fetter, Dispersion of atmospheric air pollution in summer and winter season Environmental Monitoring and Assessment 189, 605 (2017) doi:10.1007/s10661-017-6319-2

9. B. Bessagnet, L. Menut, A. Colette, F. Couvidat, M. Dan, S. Mailler, L. Létinois, V. Pont, L. Rouïl, An Evaluation of the CHIMERE Chemistry transport model to simulate dust outbreaks across the northern hemisphere in March 2014, Atmosphere 8, 251 (2017) doi:10.3390/atmos8120251

10. P. Gaffron, Urban transport, environmental justice and human daily activity patterns, Transport Policy 20, 114-27 (2012) doi:10.1016/j.tranpol.2012.01.011

11. L. Menut, A. Goussebaile, B. Bessagnet, D. Khvorostiyanov, A. Ung, Impact of realistic hourly emissions profiles on air pollutants concentrations modelled with CHIMERE, Atmospheric Environment 49, 233-44 doi:10.1016/j.atmosenv.2011.11.057

(2012)

12. C. Hendriks, R. Kranenburg, J. Kuenen, R. van Gijlswijk, R. W. Kruit, A. Segers, H. D. Van der Gon, M. Schaap, The origin of ambient particulate matter concentrations in the Netherlands, Atmospheric Environment 69, 289-303 (2013) doi:10.1016/j.atmosenv.2012.12.017

13. P.J.H. Builtjes, M. van Loon, M. Schaap, S. Teeuwisse, A.J.H.Visschedijk, J.P. Bloos, Project on the modelling and verification of ozone reduction strategies: contribution of TNO-MEP (Apeldoorn, TNO report MEP-R2003/166, 2003)

14. M. Shaap, R.M.A. Timmermans, M. Roemer, G.A. C. Boersen, P.J.H. Builtjes, The LOTOS-EUROS model: description, validation and latest developments Int. J. 
Environment and Pollution 32, 270-90 (2008) doi: 10.1504/IJEP.2008.017106

15. H.D. van der Gon, C. Hendriks, J. Kuenen, A. Segers, A. Visschedijk, Description of current temporal emission patterns and sensitivity of predicted $A Q$ for temporal emission patterns (Ultrecht, TNO report. EU FP7 MACC deliverable report D_D-EMIS_1.3, 2011)

16. B. Bessagnet, G. Pirovano, M. Mircea, C. Cuvelier, A. Aulinger, G. Calori, ..., L. White, Presentation of the EURODELTA III intercomparison exercise-evaluation of the chemistry transport models' performance on criteria pollutants and joint analysis with meteorology, Atmospheric Chemistry and Physics 16, 12667-701 (2016) doi:10.5194/acp-16-12667-2016

17. M. van Loon, R. Vautard, M. Schaap, R. Bergström, B. Bessagnet, J. Brandt, ..., P. Wind, Evaluation of longterm ozone simulations from seven regional air quality models and their ensemble Atmospheric Environment
41

2083-97

(2007)

doi:10.1016/j.atmosenv.2006.10.073

18. B. de Foy, City-level variations in NOx emissions derived from hourly monitoring data in Chicago Atmospheric Environment 176 128-39 (2018) doi:10.1016/j.atmosenv.2017.12.028

19. G. Wielgosiński, J. Czerwińska, O. Namiecińska, R. Cichowicz, Smog episodes in the Lodz agglomeration in the years 2014-17, E3S Web of Conferences 28, $01039 \quad$ (2018) doi:10.1051/e3sconf/20182801039

20. B. Dębski, A. Olecka, K. Bebkiewicz, I. Kargulewicz, J. Rutkowski, D. Zasina, M. Zimakowska-Laskowska, M. Żaczek, National balance of SO2, $\mathrm{NOx}, \mathrm{CO}, \mathrm{NH} 3$, NMLZO, dust, heavy metals and TZO in the SNAP and NFR classification system. Basic report (Warsaw, The National Centre for Emissions Management (KOBiZE), 2015) 